\title{
Body fatness in sedentary and active students with different body mass index
}

\author{
Marzena Malara $^{1}$, Grażyna Lutosławska ${ }^{1}$, Krzysztof Mazurek ${ }^{2}$, Anna Kęska ${ }^{1}$, Joanna Tkaczyk ${ }^{1}$ \\ ${ }^{1}$ Faculty of Biomedical Sciences, Józef Piłsudski University of Physical Education, Warsaw, Poland; ${ }^{2}$ Olsztyn College, \\ Department of Health Sciences, Olsztyn, Poland
}

\begin{abstract}
Study aim: Numerous data have indicated that body fat stores undergo complicated regulation by genetic and environmental factors, including physical activity. However, the majority of studies did not take into account this aspect of lifestyle in proposed body fat limits. In this context it seems that a more precise and reliable classification of body fat is provided by the American Council on Exercise (ACE), which distinguishes individuals not only with respect to sex but also activity level.

Material and methods: A total of 793 students (312 sedentary and 481 active) volunteered to participate in the study. Among sedentary participants 147 were male and 165 female. Among active subjects 206 were male and 275 were female. Active subjects were engaged in different modes of physical activity according to the study program. In all participants body mass index (BMI) was calculated. In participants with BMI 18.5-24.9 and BMI $\geq 25$ body fat was determined using four skinfold measurements. Thereafter participants were classified according to the percentage of body fat using ranges for males and females provided by the American Council on Exercise (ACE) (essential fat, athletes, fitness, average and obese fatness).

Results: None of the sedentary and active males with BMI 18.5-24.9 had high (obese) fat. In contrast, in sedentary males with BMI $\geq 2516.4 \%$ were obese vs. 1.8\% of obese active ones. In sedentary females BMI from 18.5 to 24.9 did not exclude obesity, which was found in $16.9 \%$ of participants. In sedentary females with BMI $\geq 25$ most of the subjects (97.1\%) were obese. In contrast, in active females with $\mathrm{BMI} \geq 25$ a similar percentage of participants had average and obese fat (53.3\% and 46.7 , respectively).

Discussion: Our study clearly demonstrated that BMI as a simple measure of body composition provides false information concerning true adiposity in physically active male and female students. A similar BMI did not exclude marked differences in the percentage of body fat in sedentary and active students.
\end{abstract}

Keywords: Body mass index - Sex - Physical activity - Body fatness

\section{Introduction}

Numerous data have indicated that body fat stores undergo complicated regulation by genetic and environmental factors including physical activity $[3,11,22]$. However, the majority of studies concerning norms of body fat stores did not take into account this aspect of lifestyle in proposed fat limits. In this context it seems that more precise and reliable classification of body fat is provided by the American Council on Exercise (ACE), which distinguishes individuals not only with respect to sex but also activity levels [2]. Moreover, its practical use in fatness evaluation was confirmed in studies concerning soldiers and firefighters, i.e. in professions characterized by high physical activity levels $[12,16,26]$.
It should be stressed that until now widely accepted norms of healthy and unhealthy percentage of body fat are not widely accepted. Abernathy and Black [1] proposed that the healthy percentage of body fat is $12-20 \%$ and $20-30 \%$ for men and women, respectively. However, in the literature different norms of fatness were proposed, but they are close to those established by Abernathy and Black, with higher values in females vs. males $[13,25,28]$. Thus, it is clear that body fatness shows sex-related differences which are not included in BMI and possibly brings about false determination of fat stores.

Polish physical education students are engaged in different modes of activity according to the study program (swimming, games, gymnastics, rhythmics and dance) and some of them are also engaged in high-performance sport at the academic level. However, there is a lack of 
data concerning evaluation of their fatness according to ACE standards.

\section{Purpose of the study}

Thus, this study was undertaken and aimed at determination of body fat according to ACE limits in active and sedentary students of both sexes previously classified by the BMI standard established by the World Health Organization (WHO) [15].

\section{Materials and methods}

\section{Participants}

Participants were recruited by word of mouth and advertisements in student dormitories. A total of 481 active participants (206 males and 275 females) were recruited from the Faculty of Physical Education. Their physical activity was briefly established from self-reported weekly hours of different activities according to the study program and equaled 6-8 h/week. They participated in different forms of physical activity according to their study program (swimming, games, martial arts and running). Students engaged in high performance sport were excluded from the study. A total of 312 sedentary subjects not engaging in any regular activity (147 males and 165 females) characterized by physical activity not exceeding $1.5 \mathrm{~h} /$ week (gymnastics and/or games) were accepted as sedentary. They were recruited from other universities and colleges. Each participant provided written consent for participation in the study.

\section{Anthropometric measures}

In all participants body weight and height were measured using standard medical equipment. The height of the body was measured with an anthropometer with an accuracy of $1 \mathrm{~mm}$. Body weight was measured using medical scales, in the morning on an empty stomach, without clothing. The result was read with an accuracy of $0.1 \mathrm{~kg}$. Thereafter all subjects were classified according to BMI standards established by the World Health Organization (WHO) as underweight (BMI < 18.5), normal weight (BMI 18.5-24.9) and overweigh/ obese (BMI $\geq 25$ ) (Table 1). Thereafter, due to the low number of subjects with $\mathrm{BMI}<18.5$ this group of males and females was excluded from further procedure and body fat determination was performed in participants with normal and higher than normal BMI.

Taking into account active students' participation in numerous daily activities and limits of the bio-impedance

Table 1. Anthropometric characteristics of participants with normal and overweight/obese BMI (mean $\pm \mathrm{SD}$ )

\begin{tabular}{|c|c|c|c|c|}
\hline \multirow{2}{*}{ Variable BMI } & \multicolumn{2}{|c|}{ Males } & \multicolumn{2}{|c|}{ Females } \\
\hline & Sedentary & Active & Sedentary & Active \\
\hline $18.5-24.9$ & $\begin{array}{c}\mathrm{n}=80 \\
(54.4 \%)^{*}\end{array}$ & $\begin{array}{l}\mathrm{n}=146 \\
(70.9 \%)\end{array}$ & $\begin{array}{l}\mathrm{n}=112 \\
(67.9 \%)\end{array}$ & $\begin{array}{l}\mathrm{n}=245 \\
(89.0 \%)\end{array}$ \\
\hline Age [yrs] & $22.7 \pm 1.8$ & $20.4 \pm 1.5$ & $23.1 \pm 6.6$ & $20.7 \pm 1.5$ \\
\hline Weight [kg] & $73.5 \pm 9.0$ & $73.8 \pm 6.4$ & $59.3 \pm 6.5$ & $60.2 \pm 5.6$ \\
\hline Height $[\mathrm{cm}]$ & $180.0 \pm 7.1$ & $181.5 \pm 6.3$ & $165.9 \pm 6.1$ & $168.1 \pm 6.0$ \\
\hline Fat $[\%]$ & $13.9 \pm 4.2$ & $11.8 \pm 3.7^{\mathrm{e}}$ & $25.9 \pm 5.3$ & $23.4 \pm 4.7^{\mathrm{e}}$ \\
\hline Fat $[\mathrm{kg}]$ & $10.2 \pm 3.8$ & $8.7 \pm 3.1$ & $15.4 \pm 4.5$ & $14.2 \pm 3.6$ \\
\hline LBM [kg] & $63.3 \pm 7.0$ & $65.1 \pm 6.5$ & $43.9 \pm 3.2$ & $46.0 \pm 3.9$ \\
\hline$\geq 25$ & $\begin{array}{c}\mathrm{n}=67 \\
(45.5 \%)\end{array}$ & $\begin{array}{l}(\mathrm{n}=54) \\
(26.2 \%)\end{array}$ & $\begin{array}{c}n=34 \\
(20.6 \%)\end{array}$ & $\begin{array}{l}\mathrm{n}=15 \\
(5.5 \%)\end{array}$ \\
\hline Age [yrs] & $24.9 \pm 6.1^{\mathrm{a}}$ & $20.6 \pm 1.3$ & $23.7 \pm 8.0$ & $21.2 \pm 1.8$ \\
\hline Weight [kg] & $92.0 \pm 11.0^{\mathrm{a}}$ & $88.0 \pm 7.3^{b}$ & $80.6 \pm 11.0^{\mathrm{c}}$ & $78.0 \pm 9.6^{\mathrm{d}, \mathrm{e}}$ \\
\hline Height $[\mathrm{cm}]$ & $180.2 \pm 6.5^{\mathrm{a}}$ & $180.1 \pm 6.3$ & $165.8 \pm 6.1$ & $169.7 \pm 6.1$ \\
\hline Fat $[\%]$ & $20.1 \pm 4.8^{\mathrm{a}}$ & $14.4 \pm 5.3^{\mathrm{b}, \mathrm{e}}$ & $37.5 \pm 3.8^{c}$ & $30.8 \pm 4.4^{\mathrm{d}, \mathrm{e}}$ \\
\hline Fat $[\mathrm{kg}]$ & $18.8 \pm 5.7^{\mathrm{a}}$ & $12.2 \pm 5.6^{\mathrm{b}, \mathrm{e}}$ & $30.6 \pm 6.4^{c}$ & $24.3 \pm 6.3^{\mathrm{d}, \mathrm{e}}$ \\
\hline LBM [kg] & $73.3 \pm 8.0^{\mathrm{a}}$ & $75.8 \pm 6.5^{\mathrm{b}, \mathrm{e}}$ & $50.6 \pm 5.1^{\mathrm{c}}$ & $53.7 \pm 4.6^{\mathrm{d}, \mathrm{e}}$ \\
\hline
\end{tabular}

* in brackets - percent of participants; ${ }^{\mathrm{P}}<0.001$ - significantly higher vs. sedentary males with normal $\mathrm{BMI}$; ${ }^{\mathrm{P}}<0.001-$ significantly higher vs. active males with normal BMI; ${ }^{\mathrm{P}}<0.001$ - significantly higher vs. sedentary females with normal $\mathrm{BMI}$; ${ }^{\mathrm{d}} \mathrm{P}<0.001-$ significantly higher vs. active females with normal BMI; ${ }^{\mathrm{e}}<0.001$ - significantly different in active vs. sedentary counterparts. 
procedure concerning fluid consumption [7], a decision was made to evaluate body fat using skinfold measurements (biceps, triceps, suprailiac and subscapular) and fatness calculation according to Durnin and Womersley [8]. This method is rapid and low-cost and measurements can be performed not only in the laboratory but also in other places where students are available during exercise practices and/or training. Moreover, its reliability has been confirmed in several studies in physically active individuals $[10,17,20]$. All measurements were made by a trained technician and were repeated twice but in the case of discrepancy were repeated for the third time. After the determination of body fat participants were classified according to fat norms proposed by the American Council on Exercise (essential, athletic, fitness, average and obese fat) [2]. All procedures were accepted by the local ethics committee.

\section{Data analysis}

Data are presented as means and standard deviations. All calculations were performed using Statistica v. 10 (StatSoft Ilinois, USA). All data were tested for normality using the Shapiro-Wilk test. Statistical significance was tested using the Mann-Whitney test. This test was applied for comparison of data with respect to BMI and physical activity. Reference values of body fatness were established by the ACE with respect to gender, the level of physical activit and BMI.

\section{Results}

The anthropometric characteristics of participants with normal BMI and higher than normal BMI are presented in Table 1. Irrespectively of physical activity in all groups with BMI $>25$ the percentage of body fat was higher than in their counterparts with normal BMI $(\mathrm{P}<0.001)$.
Additionally, in all participants physical activity significantly decreased body fat stores $(\mathrm{P}<0.001)$.

The anthropometric characteristics of participants according to BMI and physical activity are presented in Table 2. In active males and females the percentage of participants with normal BMI was higher vs. their sedentary counterparts $(\mathrm{P}<0.004$ and $\mathrm{P}<0.001$ in males and females, respectively). In active males with $\mathrm{BMI} \geq 25$ the percentage of subjects was lower in comparison with sedentary ones $(\mathrm{P}<0.02)$. However, in active females there was a tendency for a lower frequency of subjects with $\mathrm{BMI} \geq 25(\mathrm{P}<0.100)$.

In sedentary males a similar percentage of participants $(43.8 \%$ and $37.5 \%)$ was characterized by athletic and fitness body fat (Table 3). In contrast, in active males most of the participants $(64.4 \%)$ with normal BMI were characterized by athletic fat with a minority with essential, fitness and average fat $(\mathrm{P}<0.001)$. None of the sedentary and active males with BMI 18.5-24.9 had high (obese) fat. In contrast, in sedentary males with BMI $\geq 25$ most subjects $(53.7 \%)$ had average fat, while a minority were obese $(16.4 \%, \mathrm{P}<0.03)$. In contrast, in active males with $\mathrm{BMI} \geq 25,48.1 \%$ of subjects had athletic fat with a similar percentage of students ( $20.4 \%$ vs. $27.8 \%)$ with fitness and average fat. In active males with BMI $>25$ only $1.8 \%$ were obese.

In sedentary females, BMI 18.5 to 24.9 did not exclude obesity, which was found in $16.9 \%$ of participants (Table 4). However, a similar percentage of sedentary females ( $29.5 \%$ vs. $38.4 \%)$ were characterized by fitness and average fat. In active females with normal BMI $38.8 \%$ had average body fat, which did not differ in comparison with fitness fat, but was significantly higher $(\mathrm{P}<0.03)$ vs. participants with athletic, essential and obese fat. In sedentary females with BMI $\geq 25$ most subjects (97.1\%) were obese in comparison to average fat $(\mathrm{P}<0.001)$. In contrast, in active females with BMI $\geq 25$ a similar percentage of

Table 2. Participants' classification according to BMI and physical activity

\begin{tabular}{ccccc}
\hline \multirow{2}{*}{ BMI } & \multicolumn{2}{c}{ Males } & \multicolumn{2}{c}{ Females } \\
\cline { 2 - 5 } & $\begin{array}{c}\text { Sedentarny } \\
(\mathrm{n}=147)\end{array}$ & $\begin{array}{c}\text { Active } \\
(\mathrm{n}=206)\end{array}$ & $\begin{array}{c}\text { Sedentarny } \\
(\mathrm{n}=165)\end{array}$ & $\begin{array}{c}\text { Active } \\
(\mathrm{n}=275)\end{array}$ \\
\hline \multirow{2}{*}{$<18.5$} & - & $2 . \%^{*}$ & $11.5 \%$ & $5.5 \%$ \\
& & $(6)$ & $(19)$ & $(15)$ \\
$18.5-24.9$ & $54.4 \%$ & $70.9 \%^{\mathrm{a}}$ & $67.9 \%$ & $89 \%^{\mathrm{c}}$ \\
& $(80)$ & $(146)$ & $(112)$ & $(245)$ \\
$\geq 25.0$ & $45.5 \%$ & $26.2 \% \mathrm{~b}$ & $20.6 \%$ & $5 . \%^{\mathrm{d}}$ \\
& $(67)$ & $(54)$ & $(34)$ & $(15)$ \\
\hline
\end{tabular}

* percent of participants with different BMI; in brackets - number of subjects; ${ }^{\text {aP }}<0.004$ - significantly higher vs. sedentary males; ${ }^{\text {b }}<0.02-$ significantly lower vs. sedentary males; ${ }^{\mathrm{c}}<0.001$ - significantly higher vs. sedentary females; ${ }^{\mathrm{d}}<0.100$ - tendency to lower value in comparison with sedentary females. 
Table 3. Reference values of body fatness established by the ACE in male sedentary and active students classified as normal and overweight/obese according to BMI

\begin{tabular}{|c|c|c|c|c|c|}
\hline \multirow{2}{*}{$\begin{array}{l}\text { ACE } \\
\text { classification }\end{array}$} & \multirow[b]{2}{*}{ Body fat $[\%]$} & \multicolumn{2}{|c|}{ BMI 18.5-24.9 } & \multicolumn{2}{|c|}{ BMI $\geq 25$} \\
\hline & & $\begin{array}{l}\text { Sedentary males } \\
\quad(\mathrm{n}=80)\end{array}$ & $\begin{array}{l}\text { Active males } \\
(\mathrm{n}=146)\end{array}$ & $\begin{array}{l}\text { Sedentary males } \\
\qquad(\mathrm{n}=67)\end{array}$ & $\begin{array}{c}\text { Active males } \\
(\mathrm{n}=54)\end{array}$ \\
\hline Essential & $2.0-5.0$ & $\begin{array}{c}2.5 \% * \\
(2)\end{array}$ & $\begin{array}{c}7.5 \% \\
(11)\end{array}$ & - & $\begin{array}{c}1.8 \% \\
(1)\end{array}$ \\
\hline Athletic & $6.0-13.0$ & $\begin{array}{c}43.8 \% \mathrm{a}^{\mathrm{a}} \\
(35)\end{array}$ & $\begin{array}{c}64.4 \% \mathrm{~b} \\
(94)\end{array}$ & $\begin{array}{l}7.7 \% \\
(5)\end{array}$ & $\begin{array}{l}48.1 \% \\
(26)\end{array}$ \\
\hline Fitness & $14.0-17.0$ & $\begin{array}{c}37.5 \% \\
(30)\end{array}$ & $\begin{array}{c}22.6 \% \\
(33)\end{array}$ & $\begin{array}{l}22.4 \% \\
(15)\end{array}$ & $\begin{array}{l}20.4 \% \\
(11)\end{array}$ \\
\hline Average & $18.0-24.0$ & $\begin{array}{c}16.2 \% \\
(13)\end{array}$ & $\begin{array}{l}5.5 \% \\
(8)\end{array}$ & $\begin{array}{c}53.7 \% \mathrm{c}^{\mathrm{c}} \\
(36)\end{array}$ & $\begin{array}{l}27.8 \% \\
(15)\end{array}$ \\
\hline Obese & $>25.0$ & & - & $\begin{array}{l}16.4 \% \\
(11)\end{array}$ & $\begin{array}{l}1.8 \% \\
(1)\end{array}$ \\
\hline
\end{tabular}

* percent of participants; in brackets - number of subjects; ${ }^{\text {P }}<0.05$ - significantly higher vs. sedentary males with average and essential fat; ${ }^{b} \mathrm{P}<0.001-$ significantly higher vs. active males with essential, average and fitness fat; ${ }^{\mathrm{C}} \mathrm{P}<0.03$ - significantly higher vs. sedentary ones with athletic, fitness and obese fat.

Table 4. Reference values of body fatness established by the ACE in female sedentary and active students classified as normal and overweight/obese according to BMI

\begin{tabular}{|c|c|c|c|c|c|}
\hline \multirow{2}{*}{$\begin{array}{l}\text { ACE } \\
\text { classification }\end{array}$} & \multirow[b]{2}{*}{ Body fat [\%] } & \multicolumn{2}{|c|}{ BMI 18.5-24.9 } & \multicolumn{2}{|c|}{$\mathrm{BMI}>25$} \\
\hline & & $\begin{array}{l}\text { Sedentary females } \\
\quad(\mathrm{n}=112)\end{array}$ & $\begin{array}{l}\text { Active females } \\
\quad(\mathrm{n}=245)\end{array}$ & $\begin{array}{l}\text { Sedentary females } \\
\quad(\mathrm{n}=34)\end{array}$ & $\begin{array}{l}\text { Active females } \\
\quad(\mathrm{n}=15)\end{array}$ \\
\hline Essential & $10.0-13.0$ & $\begin{array}{c}1.8 \%{ }^{*} \\
(2)\end{array}$ & $\begin{array}{c}2.4 \% \\
(6)\end{array}$ & 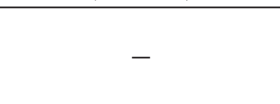 & - \\
\hline Athletic & $14.0-20.0$ & $\begin{array}{c}13.4 \% \\
(15)\end{array}$ & $\begin{array}{l}23.3 \% \\
(57)\end{array}$ & - & - \\
\hline Fitness & $21.0-24.0$ & $\begin{array}{c}29.5 \% \\
(33)\end{array}$ & $\begin{array}{c}30.6 \% \\
(75)\end{array}$ & - & - \\
\hline Average & $25.0-31.0$ & $\begin{array}{c}38.4 \%{ }^{\mathrm{a}} \\
(43)\end{array}$ & $\begin{array}{c}38.8 \% 0^{\mathrm{b}} \\
(95)\end{array}$ & $\begin{array}{l}2.9 \% \\
(1)\end{array}$ & $\begin{array}{l}53.3 \% \%^{\mathrm{d}} \\
(8)\end{array}$ \\
\hline Obese & $>32.0$ & $\begin{array}{c}16.9 \% \\
(19)\end{array}$ & $\begin{array}{c}4.9 \% \\
(12)\end{array}$ & $\begin{array}{c}97.1 \%{ }^{\mathrm{c}} \\
(33)\end{array}$ & $\begin{array}{l}46.7 \% \mathrm{e}^{\mathrm{e}} \\
\quad(7)\end{array}$ \\
\hline
\end{tabular}

* percent of participants; in brackets - number of subjects; ${ }^{\text {a }}<0.05$ - significantly higher vs. athletic, essential and obese fat; ${ }^{b} \mathrm{P}<0.03-$ significantly higher vs. athletic, essential and obese fat; ${ }^{\mathrm{C}} \mathrm{P}<0.001$ - significantly higher vs. obese subjects in others female groups; ${ }^{\mathrm{d}} \mathrm{P}<0.001-$ significantly higher vs. sedentary average females; ${ }^{\mathrm{e}} \mathrm{P}<0.001-$ significantly lower vs. sedentary average females.

participants had average and obese fat $(53.3 \%$ and $46.7 \%$, respectively).

\section{Discussion}

According to our best knowledge our study is the first which concerns classification of body fat as provided by the American Council on Exercise (ACE) with respect to sex in sedentary and physically active students and revealed that similar BMI did not exclude marked differences in the percentage of body fat. It should be stressed that a similar discrepancy between measured adiposity and BMI values in college students was noted by Richardson et al. [23] despite different limits of the percentage of body fat used in their study. In addition, numerous data indicated that BMI classification of body adiposity provided a false classification in professions characterized by high activity levels 
such as firefighters and soldiers $[6,9,16,19,21,26]$. Similarly, a significant discrepancy between body fat and BMI was noted in college students and young athletes $[4,12,24,27,30]$. This suggestion seems to be especially important in young adults characterized by high contribution of fat free mass to total body weight but also in elderly ones characterized by high contribution of fat mass to total body weight [5]. On the other hand, our data are in agreement with previous study of Heo at al. [14] which established that body fat gradually increases with increasing BMI. Moreover, our results showed that irrespectively of physical activity obesity expressed as the percentage of body fat higher than 32 is more frequent in female vs. male students. This finding is of importance taking into account studies which indicated higher obesity frequency in females vs. males and age-related changes in obesity progression $[13,18]$.

Precise evaluation of body fat according to ACE revealed marked sex - and activity-related differences in suitability of BMI as an index of fatness. True obesity, i.e. excess of body fat, was noted exclusively in sedentary males with BMI higher than 25 . In contrast, obese females were noted in sedentary females with normal BMI but mostly in sedentary females with BMI $>25$. In addition, a high percentage of active females with BMI $>25$ were obese. Thus, it could be tentatively postulated that BMI, irrespectively of physical activity, is a better index of obesity in females than in males. It should be stressed that this suggestion is in agreement with data of Wilson et al. [29] which indicated that $48.3 \%$ of males but only $24.0 \%$ of females with healthy body fat were classified as overweight/obese according to BMI values.

\section{Conclusions}

Our study clearly demonstrated that BMI as a simple measure of body composition provides false information concerning true adiposity in physically active male and female students. In male students excessive body fat was observed exclusively in sedentary ones with BMI $\geq 25$. In contrast, in female participants excessive body fat was noted in sedentary ones with normal BMI, but mostly in sedentary ones with BMI $\geq 25$. However, in active females a high percentage of participants with BMI $\geq 25$ were obese. Thus, BMI values in students, but especially in females, have to be interpreted with caution. This issue seems to be important in the young population due to possible health consequence later in the life but especially in men with higher risk of CVD than women.

However, our study has limitations. In selected groups of sedentary and active females with BMI $\geq 25$ the numbers of participants were low. Additionally, our participants were engaged in miscellaneous modes of physical activity, whose effects on fat mass may differ. In addition, subjects' physical activity was only briefly evaluated and expressed in hours of activity per week.

\section{Conflict of interest: Authors state no conflict of interest.}

\section{References}

1. Abernathy R.P., Black D.R. (1996) Healthy body weight: an alternative perspective. Am. J. Clin. Nutr.; 63(3Suppl): 448S-51S.

2. American Council on Exercise. https://acefitness.org.

3. Bradbury K.E., Guo W., Carins B.J., Armstrong M.E.G., Key T.J. (2017) Association between physical activity and body fat percentage, with adjustment for BMI: a large cross-sectional analysis of UK Biobank. BMJ. Open, 7: e011843. DOI:10.1136/bmjopen-2016-011843.

4. Canda A. (2017) Top level athletes with a body mass index of 30 or higher. Obesity or good muscle development? Apunt. Med. Esport., 52: 29-36.

5. Carpenter C.L., Yan, E., Chen S., Hong, K., Arechiga A., Kim W.S., Deng M., Li, Z., Heber, D. (2013) Body fat and body mass index among a multiethnic sample of college-age men and women.. J. Obes., DOI: 10.1155/2013/790654.

6. Choi B., Steiss D., Garcia-Rivas J., Kojaku S., Schnall P., Dobson M., Baker D. (2016) Comparison of body mass index with waist circumference and skinfold-based percent body fat in firefighters: adiposity classification and associations with cardiovascular risk factors. Int. Arch. Occup. Environ. Health, 89: 435-448.

7. Dixon C.B., Ramos L., Fitzgerald E., Reppert D., Andreacci J.L. (2009) The effect of acute fluid consumption on measures of impedance and percent body fat estimated using segmental bioelectrical impedance analysis. Eur. J. Clin. Nutr., 63; 1115-1122.

8. Durnin J.V.G.A., Womersley J. (1974) Body fat assessed from total body density and its estimation from skinfold thickness: measurements on 481 men and women aged 16 to 72 years. Br. J. Nutr., 32: 77-97. DOI: 10.1079/ BJN19740060.

9. Friedl K.E. (2012) Body composition and military performance - many things to many people. J. Strength. Cond. Res., 26: S87-100.

10. Garido-Chamorra R., Sirvent-Belando J.E., GonzalesLorenzo M., Blasco-Lafarga C., Roche E. (2012) Skinfold sum: Reference values for top athletes. Int. J. Morphol., 30: 803-809.

11. Gonçalves da Silva B., Crochemore-da Silva I., Ekelund U., Brage S., Ong K.K., De Lucia Rolfe E., Peixoto Lima N., Ginar da Silva S., Araujo de Franca G.V., Lessa Horta B. (2019) Associations of physical activity and sedentary time with body composition in Brazilian 
young adults. Sci. Reports, 9: 544. DOI: 10.1038/s41598019-41935-2.

12. Grier T., Canham-Chervak M., Sharp M., Johnes B.H. (2015) Does body mass index misclassify physically active young men. Prev. Med. Rep., 2: 483-487.

13. He X., Li Z., Tang X., Zhang L., Wang L., He Y., Jin T., Yuan D. (2018) Age- and sex-related differences in body composition in healthy subjects aged 18 to 82 years. Medicine, 97: 25(e11152). DOI: 10.1097/ MD.0000000000011152.

14. Heo M., Faith M.S., Pietrobelli A., Heymsfield S.B. (2012) Percentage of body fat cutoffs by sex, age, and race-ethnicity in the US adult population from NAANES 1999-2005. Am. J. Clin. Nutr., 95: 594-602. DOI: 10.3945ajen.111.025171.

15. http://www.euro.who.int/health-topics/disease

16. Jitnarin N., Poston W.S.W.C., Haddock Ch.K., Jahnke S.A., Day R.S. (2014) Accuracy of body mass index-defined obesity status in US firefighters. Safety Health Work, 5: 161-164.

17. Mũller W., Fũrhapter-Rieger A., Ahamer H., Lohman T.G., Meyer N.L., Sardinha L.B. (2019) Relative body weight and standarised brightness-mode ultrasound measurement of subcutaneous fat in athlete: An international multicentre reliability study under the auspices of the IOC medical commission. Sports Med., DOI: 10.1007/ s40279-019-01192-9.

18. NCD Risk Factor Collaboration. (2017) Worldwide trends in body-mass index, underweight, and obesity from 1975 to 2016: a pooled analysis of 2416 population-based measurement studies in 128,9 million children, adolescents, and adults. Lancet, 390: 2627-2642. DOI: 10.1016/ S0140-6736(17)32129-3.

19. Ode J., Knous J., Schlaff R., Hemeyway J., Peterson J., Lowry J. (2014) Accuracy of body mass index in volunteer firefighters. Occup. Med., 64: 193-197.

20. Popadić Gačeša J., Barak O., Karaba Jakovlevic D., Klašnja A., Galić V., Drapšin M. (2011) Body mass index and body fat content in elite athletes. Exercise and Quality of Life, 3: 43-48.

21. Rašeta N., Đurić S., Zeljković N., Simović S., Vujnić M. (2016) Interrelations between body mass index, percentage of body fat, and waist-to-hip ratio among different groups of students at the University of Banja Luka. Facta Universitatis. Series: Physical Education and Sport., 14: 331-45.

22. Reddon H., Gerstein H.C., Engert J.C., Mohan V., Bosch J., Desai D., Bailey S.D., Diaz R., Yusuf S.,
Anand S.S., Meyre D. (2016) Physical activity and genetic predisposition to obesity in a multiethnic longitudinal study. Sci. Reports, 6: 18672. DOI: 10.1038/ srep18672.

23. Richardson M., Madzima T., Nepocatych S. (2019) Differences in body composition affect weight control practices and body image satisfaction in college students. Phys. Activ. Health, 3: 1-10. DOI: 10.5334/paah.28.

24. Santos D.A., Silva A.M., Matias C.N., Magalhäes J.P., Minderico C.S., Thomas D.M., Sardinha L.B. (2015) Utility of novel body indices in predicting fat mass in elite athletes. Nutrition, 31: 948-54. DOI: 10.1016/j. nut.2015.02.003.

25. Schorr M., Dichter L.E., Gerweck A.V., Valera R.D., Torriani M., Miller K.K., Bredella M.A. (2018) Sex differences in body composition and association with cardiometabolic risk. Biol. Sex. Differ., 9: 28. DOI: 101186/ s13293-018-0189-3.

26. Smee G.J., Walker A., Rattray B., Cooke J.A., Serpell B.G., Pumpa K.L. (2019) Comparison of body composition assessment methods in professional urban firefighters. Int. J. Sport. Nutr. Exerc. Metab., 29: 282-88. DOI: 10.1123/ijsnem.2018-0040.

27. Tafeit E., Cvirn G., Lamprecht M., Hohensinn M., Moeller R., Hamlin M., Horeisi R. (2019) Using body mass index ignores the intensive training of elite special force personnel. Exp. Biol. Med., 244: 873-879. DOI: $10.1177 / 15353702119848986$.

28. Wellens R.I., Roche A.F., Khamistr H.J., Jacksons A.S., Pollock M.L., Siervogel R.M. (1996) Relationship between the body mass index and body composition. Obes. Res., 4: 35-44.

29. Wilson O.W.A., Zou Z.H., Bopp M., Bopp Ch.M. (2019) Comparison of obesity classification methods among college students. Obes. Res. Clin. Pract., 13: 430-34.

30. Zanovec M., Lakkakula A.P., Johnson J.G., Turri G. (2009) Physical activity is associated with percent body fat and body composition but not body mass index in white and black college students. Int. J. Exerc. Sci., 2: 175-185.

\section{Received 15.09.2020 \\ Accepted 26.11.2020}

(C) University of Physical Education, Warsaw, Poland 